
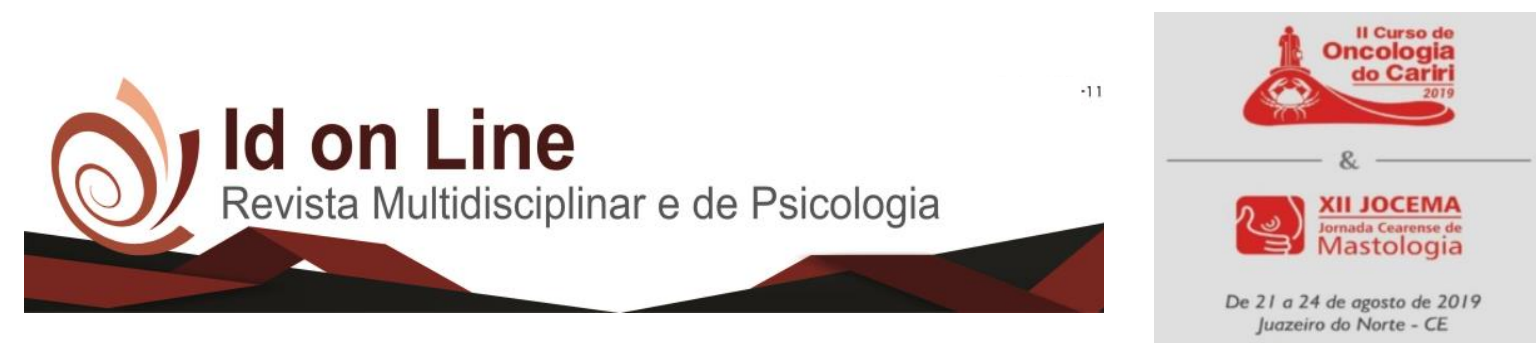

DOI: 10.14295/idonline.v13i46.1996

Resumo

\title{
REAÇÕES ALÉRGICAS ASSOCIADAS A QUIMIOTERÁPICOS E IMPLICAÇÕES NOS CUIDADOS NECESSÁRIOS A PACIENTES ONCOLÓGICOS IMUNODEPRIMIDOS: NOTAS INTRODUTÓRIAS
}

\author{
Helen Fernanda de Oliveira Sousa ${ }^{1}$; Paula Gabriella de Sousa Araújol ${ }^{1}$ Djailson Ricardo Malheiro ${ }^{2}$
}

Introdução: Apesar dos imensos avanços na evolução do tratamento do câncer a fim de reduzir os efeitos colaterais e toxicológicos das drogas antineoplásicas, o tratamento quimioterápico afeta de forma sistêmica todas as células do corpo humano apresentando baixa especificidade na destruição apenas de células neoplásicas o que pode desencadear uma série de reações alérgicas, as quais, podem ser graves e fatais para os pacientes oncológicos, dentre eles aqueles que se encontram imunodeprimidos devido ao uso de quimioterápicos. Objetivo: tem-se por objetivo enfatizar o conhecimento acerca de que muitos quimioterápicos apresentam caráter alergênicos e que o cuidado tanto durante a aplicação da medicação quanto ao longo de todo o tratamento é imprescindível, principalmente em pacientes imunocomprometidos. Método: A partir de uma revisão de literatura foram analisados artigos científicos em bases de dados como PUBMED, Scielo e google acadêmico utilizando como descritor, principalmente, quimioterapia associada a processos alérgicos, imunossupressão oncológica e efeitos colaterais dos corticoides. Resultados: todas as drogas quimioterápicas assim como qualquer outra medicação podem desencadear reações alérgicas, entretanto algumas drogas apresentam-se mais propensas a desencadear tais reações como sais de platina, taxanos e procarbazina, por exemplo (SILVA, 2015). A maioria das reações de hipersensibilidade apresentam-se clinicamente como urticária, prurido, angioedema, rash cutâneo, broncoespasmo e anafilaxia (SILVA, 2015). Nessa perspectiva, tais reações devem ser combatidas a fim de evita-se o agravamento clinico do paciente. Conclusão: Considera-se importante que os profissionais da saúde devem ter o conhecimento prévio sobre as drogas especificas que apresentam alto risco reacional alérgico, no intuito, de prevenir reações de hipersensibilidade nos pacientes. Sendo assim, o uso de anti-histamínicos e glicocorticoides infundidos antes ou associados a quimioterápicos devem ser empregados como uma alternativa viável, além de tomadas de decisões importantes sobre se aquele quimioterápico deve ser substituído ou descontinuado em prol do bem-estar do paciente, verificando-se o custo-benefício pautado na doença. Além disso, é necessário cautela ao receitar corticoides a longo prazo ou de forma indiscriminada a pacientes oncológicos principalmente os imunodeprimidos em casos de reações alérgicas, já que tais drogas podem baixar mais ainda a imunidade do paciente.

Palavras-Chave: Quimioterapia. Reações alérgicas. Imunodeprimidos.

\footnotetext{
${ }^{1}$ Acadêmica no curso de medicina Faculdade de Medicina Estácio de Juazeiro do Norte.

2 Prof. Me. da Faculdade de Medicina Estácio de Juazeiro do Norte.
} 


\section{Referências}

BERTOLAZZI, Luana Gaino et al. Incidência e caracterização de reações adversas imediatas à infusão de quimioterápicos em hospital sentinela. Arquivos de Ciências da Saúde, v. 22, n. 3, p. 84-90, 2015.

BRANDÃO, Igor Ventura; RAMOS, Anne Caroline Santos; SOUZA, Isana Carla Leal. Leucopenia Secundária ao Uso de Glicocorticóides. Semana de Pesquisa da Universidade TiradentesSEMPESq, n. 18, 2018.

CAVALER, Aline Warmling Warmling et al. Assistência de enfermagem frente aos efeitos colaterais em pacientes submetidos a quimioterapia. Revista Interdisciplinar de Estudos em Saúde, v. 6, n. 1, p. 200-212, 2017.

COSTA, Ana Carolina Assis et al. Pacientes em uso crônico de prednisona: perfil Clínico e laboratorial. Revista Eletrônica de Farmácia, v. 15, 2018.

ERRANTE, Paolo Ruggero et al. Mecanismo de Ação e Resistência ao Uso de Glicocorticóides. Revista de Pesquisa e Inovação Farmacêutica, v. 6, n. 2, 2015.

FERNANDES, Carolina De Lima et al. PERFIL DOS PACIENTES EM TRATAMENTO QUIMIOTERÁPICO COM CAPECITABINA NO HOSPITAL UNIVERSITÁRIO DE SANTA MARIA/RS. In: $6^{\circ}$ Congresso Internacional em Saúde. 2019.

GABRIEL, Gabriela Hadler et al. Quimioterapia, Hormonioterapia e novas alternativas de tratamento do adenocarcinoma mamário. Enciclopédia biosfera, Goiânia, v. 14, n. 26, p. 583, 2017.

GUIMARÃES, Rita de Cássia Ribeiro et al. Ações de enfermagem frente às reações a quimioterápicos em pacientes oncológicos. Revista de Pesquisa Cuidado é Fundamental Online, v. 7, n. 2, p. 2440$2452,2015$.

KAMEO, Simone Yuriko et al. Febrile neutropenia recurrence after chemotherapy in patients with breast cancer/Neutropenia febril de recorrência pós quimioterapia em paciente com câncer de mama/Febril recurrencia neutropenia después de la quimioterapia en pacientes con cáncer.. Revista de Enfermagem da UFPI, v. 4, n. 2, p. 111-8, 2015.

KANDA, Márcia Helena et al. A percepção dos familiares cuidadores sobre o tratamento quimioterápico em crianças e adolescentes. Cogitare Enfermagem, v. 19, n. 1, p. 84-88, 2014.

LIMA, Joana; SOUSA, Marta; ANDRADE, Pedro. Psoríase Inaugural Após Tratamento com Docetaxel. Outubro, 2017.

NUNES, Dejair dos Santos. Reações adversas relacionadas ao uso de corticóides em idosos: revisão de literatura. 2016.

PEREIRA, Paulina Patente et al. Identificação, prevenção e tratamento da síndrome mão-pé induzida por quimioterapia: Uma revisão sistemática. 2019.

RAFAEL, Carla Marisa Magalhães. A enfermagem e as novas tecnologias: IGestSaúde, como promotor da autogestão dos sintomas decorrentes do tratamento de quimioterapia. 2019. Tese de Doutorado.

SCHIAVO, Morgana. Guia para dispensação de quimioterápicos via oral. 2017.

SILVA, Priscila et al. O manejo das reações agudas em quimioterapia. Acta méd.(Porto Alegre), v. 36, p. [6]-[6], 2015.

SOUSA-PINTO, Bernardo; PEREIRA, Ana Margarida; FONSECA, João Almeida. Impacto do diagnóstico de alergia a fármacos. Revista Portuguesa de Imunoalergologia , v. 25, n. 4, p. 249-258, 2017. 